\title{
COMMENTARY
}

\section{Debate on Animal Experiments in Traditional Medicine: Do We Have a Better Choice?}

\author{
Mojtaba Farjam $\bowtie$
}

\section{Dear Editor,}

I eagerly read the letter written by Daneshfard et al. [1], entitled: "Pitfalls of Animal Study: Avicenna's View."

The authors have discussed the challenge regarding the application of animal models in biomedical research. The respectable authors have written some issues claiming that the publications based on the animal counterparts have many pitfalls. However, they have not elucidated that most of these problems are also seen in human studies. For instance, publication biases due to unpublished negative results are common in human studies too. The scientific society should face all of these problems in researches not only in the animal but also in clinical eras. Moreover, inadequate systematic reviews and meta-analyses have been noted.

I agree with this problem in animal studies, however, if research on an animal model enters clinical phases, there would remain no place for animal meta-analysis reviews. In fact, narrative reviews combining animal and human results are of more interest to provide knowledge about emerging fields in the literature [2]. In contrast to clinical studies, the nearly equal animals' genetic background in a chosen strain, their standardized laboratory conditions, and similar environmental factors might satisfy the researchers not to feel much need to write so many meta-analyses.

Furthermore, the authors had better pay at-

\section{GMJ}

o2016 Galen Medical Journal

Tel/Fax: +98 7136474503

PO Box 7193616563

Email:info@gmj.ir tention to what science has earned by animal studies. We should not forget that we could not get the knowledge of basic medical sciences without animal research. If animal experiments were not available, there were no areas like physiology, pathophysiology, and pharmacology. Ethics does not permit harmful experiments on mankind. For instance, neuroscience was not as extensive as is today and the field of stem cells in biomedicine had not been born.

Another aspect of experiments goes back to drug development. Food and drug administration (FDA) is the organization responsible for approval of clinical trials. In most cases, no file of a new drug or new drug application could be opened without clear preclinical animal data for a drug to enter clinical trials.

The authors tried to claim that animal studies are against the emerging paradigm of individualized medicine.

However, individualized medicine is categorized in a separate level of research. There is no drug to be designed for one person. The tract of drug development would reach to personalized medicine after all safety concerns and efficacy issues have been clearly shown. Then, the best medication could be matched for a single person based on many issues. Pharmacogenetics and pharmacogenomics can help in this regard in future. I agree with the authors that the elements of traditional medicine about "Mezadj" might be useful to tailor personalized medicine, in some aspects.

\footnotetext{
Correspondence to:

Mojtaba Farjam, Non-Communicable Diseases Research Center, Department of Pharmacology, Fasa University of Medical Sciences, Fasa, Iran Telephone Number: +98 7153316300 Email Address : mfarjam@fums.ac.ir
} 
In fact, this field is very exciting. However, this brilliant idea has nothing to do with criticisms against animal studies in basic medicine. Furthermore, it is the responsibility of the traditional medicine scholars to show evidence regarding the effect of "Mezadjes" on the treatment of people. They should present evidence at high levels by designing clinical trials and longitudinal studies. By using scientific methods of research, the great Iranian medical scientists as Ave Sina would be better acknowledged. As their primer works in medicine, have been appreciated elsewhere, in nearly all textbooks of modern medicine. To my knowledge, there are differences among animals (including human) in drug disposition and xenobiotic metabolism. However, based on what the authors have written, I invite them to elucidate how horse and lion are different in "Mezadjes" from a human. By whom these differences have been experimented or proven. This subject might open new debates and permit novel experiments.
Specially, if these claims could be clearly addressed in laboratory animals, new paradigm shifts could emerge in pharmacological research. In other words, instead of telling stories from traditional books, isn't it better to provide evidence through hard work? Isn't it more fruitful to follow the works of modern scientists in the field of traditional medicine to produce evidence- based knowledge as what Indians have done on curcumin? [3, 4].

As a researcher, I believe in studying the history of medicine to rediscover what the traditional scientists had detected but, unfortunately, are not known today [5-8]. So I truly appreciate the authors for their letter and Galen Medical Journal (GMJ) for opening windows for these kinds of scientific debates.

[GMJ. 2016;5(4):233-34]

Keywords: Traditional Medicine; Avicenna; Mezaj; Animal Experiments

\section{References}

1. Daneshfard B, Tafazoli V, Nimrouzi M. Pitfalls of Animal Study: Avicenna's View. Galen Medical Journal. 2016;5(3):160-1.

2. Farjam M, Zhang GX, Ciric B, Rostami A. Emerging immunopharmacological targets in multiple sclerosis. Journal of the neurological sciences. 2015 Nov 15;358(1-2):22-30.

3. Farjam M, Mehrabani D, Abbassnia F, Tanideh N, Imanieh MH, Pakbaz S, et al. The healing effect of Curcuma longa on liver in experimental acute hepatic encephalopathy of rat. Comparative Clinical Pathology. 2014;23(6):1669-73.

4. Mehrabani D, Farjam M, Geramizadeh B, Tanideh N, Amini M, Panjehshahin MR. The healing effect of curcumin on burn wounds in rat. World journal of plastic surgery. 2015;4(1):29-35.

5. Farjam M. Iranian Traditional Medicine: The Need for Evidences Provided by Modern Medical Research to Prove Usefulness. GMJ. 2016;5(3):105-6.
6. Askari A, Farjam M, Zohalinezhad ME. Early reports of bone repair techniques and bone xenograft in Persian traditional medicine. Journal of integrative medicine. 2015;13(3):140-1.

7. Nadim M, Farjam M. Qutb al-Din Shirazi (1236-1311), Persian polymath physician in the medieval period. Journal of medical biography. 2016;24(3):360-2.

8. Zohalinezhad ME, Askari A, Farjam M. Clinical stories and medical histories recorded by Rhazes (865-925), the IranianIslamic physician in the medieval period. Acta medico-historica adriatica : AMHA. 2015;13 (Suppl 2):77-86. 